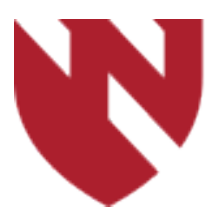

October 2021

\title{
Does Full Transfixion Incision Decrease Tip Projection in Endonasal Septoplasty with Spreader Grafts?
}

\author{
William Wesley Heckman MD \\ University of Nebraska Medical Center, Otolaryngology- Head and Neck Surgery \\ Tyler Bliss MD \\ University of Nebraska Medical Center, Otolaryngology- Head and Neck Surgery \\ Sarah Schmoker MD \\ University of Nebraska Medical Center, Otolaryngology- Head and Neck Surgery \\ Katie Geelan-Hansen MD \\ University of Nebraska Medical Center, Otolaryngology- Head and Neck Surgery
}

Tell us how you used this information in this short survey.

Follow this and additional works at: https://digitalcommons.unmc.edu/gmerj

Part of the Otolaryngology Commons, and the Plastic Surgery Commons

\section{Recommended Citation}

Heckman WW, Bliss T, Schmoker S, Geelan-Hansen K. Does Full Transfixion Incision Decrease Tip Projection in Endonasal Septoplasty with Spreader Grafts? Graduate Medical Education Research Journal.

This Brief Report is brought to you for free and open access by DigitalCommons@UNMC. It has been accepted for inclusion in Graduate Medical Education Research Journal by an authorized editor of DigitalCommons@UNMC. For more information, please contact digitalcommons@unmc.edu. 


\title{
Does Full Transfixion Incision Decrease Tip Projection in Endonasal Septoplasty with Spreader Grafts?
}

\author{
Abstract \\ The classic teaching is that full transfixion incision decreases nasal tip projection by disrupting the \\ attachment of the medial crura to the caudal septum. A significant decrease in tip projection after \\ endonasal septoplasty with spreader grafts through a full transfixion incision has not been identified at \\ our institution. A retrospective cohort study was performed at our institution. Inclusion criteria consisted \\ of patients undergoing endonasal septoplasty with spreader graft placement and available preoperative \\ and one-year postoperative photos. Patients who had undergone an open approach, cosmetic rhinoplasty, \\ had intercartilaginous incisions, or other procedures to affect tip projection were excluded. A query \\ identified 432 patients, of which 104 patients met inclusion criteria. Of these, 19 had pre and post- \\ operative photographs and were included in the final analysis. Mirror software was utilized to analyze the \\ pre and post-operative photos for tip projection using the Goode method. The change in tip projection \\ was analyzed from both left and right profile photos. The left change in nasal tip projection (or delta) was \\ $-0.010(95 \% \mathrm{Cl}-0.003,-0.017)$ and the right delta was $-0.013(95 \% \mathrm{Cl}-0.005,-0.020)$. In our pilot study of \\ 19 patients, we did not find a clinically significant change in nasal tip projection when a full transfixion \\ incision was used for the approach. In our experience, full transfixion incision is a safe and effective \\ method for improving functional status in patients without causing a significant change in nasal tip \\ projection.
}

\section{Keywords}

tip projection, endonasal septoplasty, spreader graft, full transfixion incision, rhinoplasty

\section{Creative Commons License} c) (i) $९$

This work is licensed under a Creative Commons Attribution-Noncommercial-No Derivative Works 4.0 License. 


\section{Does Full Transfixion Incision Decrease Tip Projection in Endonasal Septoplasty with Spreader Grafts?}

William Wesley Heckman ${ }^{1}$, Tyler Bliss ${ }^{1}$, Sarah Schmoker ${ }^{1}$, Katie Geelan-Hansen

'University of Nebraska Medical Center, College of Medicine, Department of Otolaryngology - Head and Neck Surgery

https://doi.org/10.32873/unmc.dc.gmerj.3.1.005

\section{Abstract}

Introduction: The classic teaching is that full transfixion incision decreases nasal tip projection by disrupting the attachment of the medial crura to the caudal septum. A significant decrease in tip projection after endonasal septoplasty with spreader grafts through a full transfixion incision has not been identified at our institution.

Methods: A retrospective cohort study was performed at our institution. Inclusion criteria consisted of patients undergoing endonasal septoplasty with spreader graft placement and available pre-operative and one-year postoperative photos. Patients who had undergone an open approach, cosmetic rhinoplasty, had intercartilaginous incisions, or other procedures to affect tip projection were excluded. A query identified 432 patients, of which 104 patients met inclusion criteria. Of these, 19 had pre- and postoperative photographs and were included in the final analysis. Mirror software was utilized to analyze the pre- and post-operative photos for tip projection using the Goode method. The change in tip projection was analyzed from both left and right profile photos.

Results: The change in left nasal tip projection (or delta) was $-0.010(95 \% \mathrm{CI}$ $-0.003,-0.017)$ and the right delta was -0.013 (95\% CI $-0.005,-0.020)$. In our study of 19 patients, we did not find a clinically significant change in nasal tip projection when a full transfixion incision was used for the approach.

Conclusion: In our experience, full transfixion incision is a safe and effective method for improving functional status in patients without causing a significant change in nasal tip projection.

\section{Introduction}

Spreader grafts are used to repair internal nasal valve dysfunction and improve airflow through the narrowest portion of the nasal cavity. ${ }^{1}$ While open rhinoplasty allows for wide visualization and precise placement of spreader grafts, it also increases postoperative edema and recovery time and creates an external scar. ${ }^{1}$ Endonasal spreader graft placement has equal efficacy as open rhinoplasty with the benefit of no external scarring, making it a desirable alternative for nasal valve repair. ${ }^{1}$ Full-transfixion incision is critical for the endonasal approach as it allows visualization of the septum for proper spreader graft placement. ${ }^{1}$

Nasal tip support has been widely described as having major and minor tip support mechanisms. ${ }^{2}$ One of the major support mechanisms is defined as the attachment of the medial crural footplate to the caudal septum. ${ }^{3}$ Full transfixion incision releases the fibrous attachment of the medial crura to the nasal septum and has been classically taught to decrease nasal tip projection. ${ }^{4}$ However, a significant decrease in tip projection after endonasal septoplasty with spreader grafts using a full transfixion incision has not been identified in patients who had undergone this procedure at our institution.

To evaluate nasal tip projection (NTP), the Goode method is commonly used for interpreting rhinoplasty photographs. ${ }^{4}$ The method uses two perpendicular lines drawn from the nasion to the alar root and the alar root to the tip of the nose. ${ }^{5} \mathrm{NTP}$ is calculated as a ratio, equaling the distance between the alar root and nasal tip divided by the distance between the nasion and nasal tip. ${ }^{5}$ This ratio can be used to relatively compare pre- and post-operative NTP as the nasion and alar root are consistent landmarks in septoplasty.

\section{Methods}

A retrospective review of a cohort of patients operated on by a single facial plastic surgeon at our institution was performed with IRB approval. Patients undergoing endonasal septoplasty with spreader graft placement with or without inferior turbinate reductions were included in the study. Endonasal septoplasty was performed using a full transfixion incision. Patients who had undergone an open approach, cosmetic rhinoplasty, had intercartilaginous incisions, or any other procedures affecting tip projection were excluded.

Our electronic medical records were queried, with 432 patients identified. Upon chart review, 328 patients were excluded, leaving 104 patients that met inclusion criteria. Of these, 19 had pre-operative and one-year post-operative photographs and were included in the final analysis. Mirror software by Canfield Imaging Systems was utilized to analyze the pre- and post-operative photos for tip projection using the Goode method. The change in tip projection was calculated and a simple two sample T-test was performed. To convert the ratio calculated by Goode's method into a theoretical measurement, a simple mathematical model was used (Fig. 1).

Theoretical calculation of tip projection change conversion to $\mathrm{mm}$ change

$2.5 \mathrm{~cm}(\mathrm{~h}) / 4.5 \mathrm{~cm}(\mathrm{v})=0.55$ ratio

Decreasing the ratio by 0.01 gives us the following:

$0.54=x \mathrm{~cm}(\mathrm{~h}) / 4.5 \mathrm{~cm}(\mathrm{v})$

$X(h)=0.54 \times 4.5 \mathrm{~cm}(\mathrm{v})$

$X(h)=2.43 \mathrm{~cm}($ a change of $0.7 \mathrm{~mm})$

Average tip projection calculation

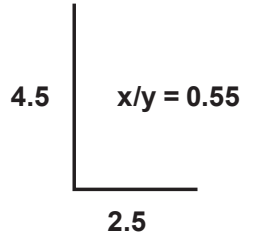

Tip projection calculation minus average change

4.5 $(0.55-0.01=0.54)$

2.43

Figure 1. Mathematical model for calculation of tip projection change to $\mathrm{mm}$ change. 


\section{Results}

Our cohort was predominately male, with 14 males and 5 females. The average age was 41 years, and average time to obtaining post-op photographs was 2.25 years. We analyzed tip projection using both the left and right profile photos. The change in left nasal tip projection (or delta) was -0.010 (95\% CI $-0.003,-0.017)$ and the right delta was $-0.013(95 \%$ CI -0.005 , -0.020). When looking at the composite delta in graphical format, we see that the changes in Goode ratio pre- and post-operative clustered in the hundredth to thousandth ratio change (Fig. 2).

To determine whether this change was clinically significant, we converted the change in Goode ratio to the millimeter change in tip projection with an algebraic model. For example, a nose with a $2.5 \mathrm{~cm}$ tip projection and $4.5 \mathrm{~cm}$ height, yields a 0.55 Goode ratio. The conversion formula is described in Fig. 1. Decreasing the Goode ratio by the 0.01 change that we saw in our cohort, we then assumed the vertical height would remain the same and solved for the horizontal tip projection. This yielded a new tip projection of $2.43 \mathrm{~mm}$. Thus a 0.01 change in Goode ratio consisted of a $0.7 \mathrm{~mm}$ change in tip projection in this theoretical model.

\section{Discussion}

Several studies contradict the classic teaching that full transfixion incision significantly alters nasal tip support and projection. It is widely taught that the major tip is supported by a columella to nasal septum attachment. Although widely taught, several cadaveric studies have failed to find a significant ligament between these two structures. ${ }^{6,7}$ Additionally, Ordonez-Ordonez et al. concluded that full transfixion incision did not cause a significant change in nasal tip projection during conventional septal surgery $^{6}$. In addition, Beaty et al. objectively evaluated nasal tip support strength and found that marginal and transfixion incisions had no significant effect on tip support. ${ }^{3}$

Calculating Goode's ratio is helpful to relatively compare pre- and post-operative digital photographs. ${ }^{4}$ To our knowledge, Goode's ratio has not been used to calculate NTP changes into a theoretical measurement before. We addressed this by utilizing a simple algebraic formula to convert relative distances into theoretical measurements, allowing us to relate the clinical insignificance of a minor change in Goode's ratio. Alternatively, developing a conversion formula for the change in Goode's ratio to a

Left Profile Change in Tip Projection

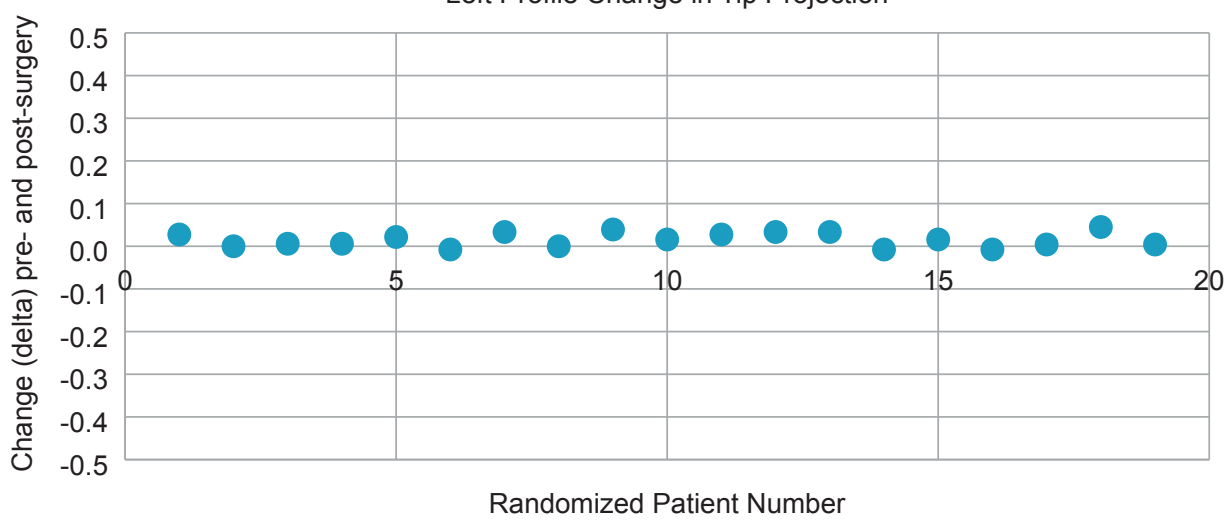

Right Profile Change in Tip Projection

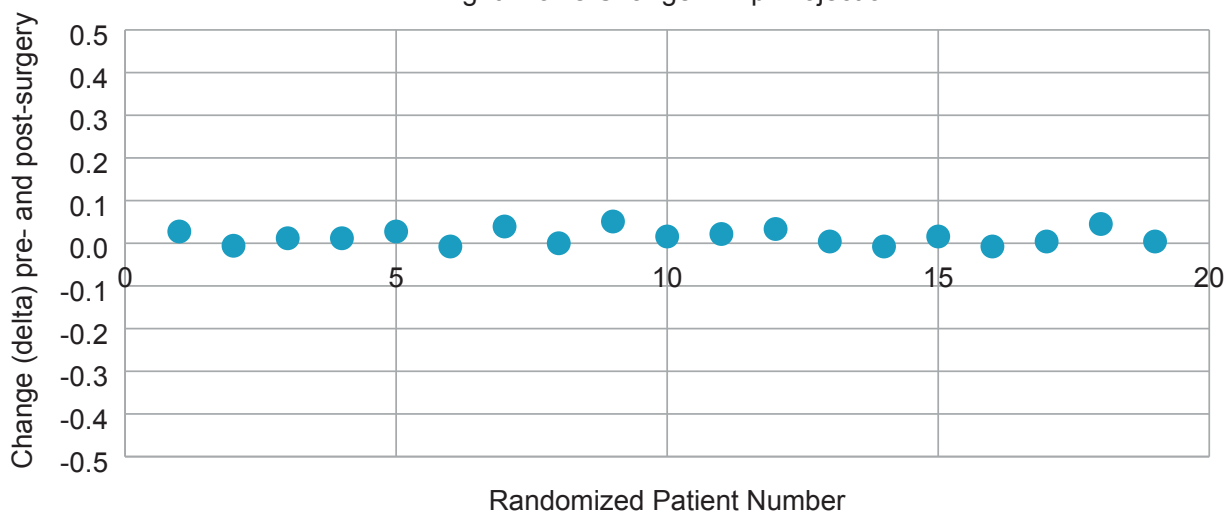

Figure 2. Left and right profile picture change in tip projection (post-surgery tip projection minus presurgery tip projection.

change in millimeter tip projection or using a projectometer to measure tip projection would be helpful for future research in this area.

In our study of 19 patients, we did not find a clinically significant change in nasal tip projection when a full transfixion incision was used for the approach. More research is needed with a larger sample size to determine the true change in mm tip projection after endonasal septoplasty with spreader grafts. In our experience, full transfixion incision is a safe and effective method for improving functional status in patients without causing a significant change in nasal tip projection.

\section{References}

1 Yoo DB, Jen A. Endonasal placement of spreader grafts: Experience in 41 consecutive patients. Arch Facial Plast Surg. 2012;14(5):318-322.

2 Tardy ME. Rhinoplasty: The Art and the Science. Philadelphia: WB Saunders Company; 1997. P. 11725.

3 Beaty MM, Dyer WK 2nd, Shawl MW. The quantification of surgical changes in nasal tip support. Arch Facial Plast Surg. 2002;4(2):82-91.

4 Solomon P, Rival R, Mabini A, Boyd J. Transfixion incision as an initial technique in nasal tip deprojection. Can J Plast Surg. 2008;16(4):224-227.

5 Ingels K, Orhan KS. Measurement of preoperative and postoperative nasal tip projection and rotation. Arch Facial Plast Surg. 2006;8(6):411-415.

6 Ordonez-Ordonez LE, Navarro-Garcia US, AnguloMartinez ES. Nasal septum to columella attachment A major tip support? Otolaryngol Head Neck Surg. 2010;143(1):60-65.

7 Han SK, Lee DG, Kim JB, Kim WK. An anatomic study of nasal tip supporting structures. Ann Plast Surg. 2004;52(2):134-139. 